\title{
Effects of Water Deficit on Growth, Biomass Allocation and Photosynthesis of $A$. senegal Seedlings from Nguru and Gujba Provinces of Yobe State, North Eastern Nigeria
}

\author{
${ }^{1,2}$ JIBO, AU; ${ }^{2}$ BARKER, MG \\ ${ }^{*}$ Department of Forestry and Wildlife Management, Federal University Dutse, P.M.B. 7156, Dustse, Jigawa State, Nigeria. \\ ${ }^{2}$ Institute of Biological and Environmental Sciences, University of Aberdeen, AB $243 U U$ Aberdeen. U.K. \\ *Corresponding AuthorEmail: jiboau@yahoo.com; jibo.au@fud.edu.ng,Tel: +2348036212419
}

\begin{abstract}
Acacia senegal (L) Willd is a multipurpose tree species that occurs throughout semi-arid Africa. Poor yields of gum from the species in the semi-arid region of Nigeria may be due to more frequent drought events. It is not yet clear whether some populations of $A$. senegal may respond differently to any encroaching drought. The effects of water deficit on growth, biomass allocation and photosynthesis of $A$. senegal seedlings from Nguru and Gujba province of Yobe state, North Eastern Nigeria were studied under glasshouse conditions for 120 days. Plants were subjected to three watering regimes; control (well-watered) conditions corresponding to $25 \%$ gravimetric water content (GWC), mild water deficit at $15 \%$ (GWC) and severe-water-deficit at $10 \%$ (GWC), respectively. There was a highly significant difference in stomata conductance among the treatments $\left(\mathrm{F}_{2,84}=11.38, \mathrm{P}<0.001\right)$ in relation to water deficit. There was no statistical difference in quantum yield between the two provenances $\left(\mathrm{F}_{1,84}=0.15, \mathrm{P}=0.695\right)$ and interaction between treatment and provenances was also not significant $\left(\mathrm{F}_{2,84}=2.14, \mathrm{P}=0.124\right)$. mean root length between the provenances were significantly different $\left(\mathrm{F}_{2,84}=0.60, \mathrm{P}<0.001\right)$ however Root length was not statistically significantbetweentreatments $\left(\mathrm{F}_{2,84}=0.60, \mathrm{P}=0.550\right)$. Plant biomass, stomata conductance, quantum yield, chlorophyll fluorescence, relative water content, root length and root: shoot ratios were highly responsive to changes in soil water. It was concluded that $A$. senegal is capable of physiological adjustment in response to soil moisture as a form of ecological adaptation.
\end{abstract}

DOI: https://dx.doi.org/10.4314/jasem.v23i12.21

Copyright: Copyright $($ C 2019 Jibo and Barker. This is an open access article distributed under the Creative Commons Attribution License (CCL), which permits unrestricted use, distribution, and reproduction in any medium, provided the original work is properly cited.

Dates: Received: 30 November 2019; Revised: 20 December 2019; Accepted: 23 December 2019

Keywords: biomass allocation, provenances, relative water content, stomata conductance.

Climate related increases in global mean temperature and changes in the world's hydrological cycle are likely to have substantial effects in some regions (IPCC, 2007).In the Sahel region of Africa, two catastrophic droughts occurred within a dry period of 25 years, from 1968 to 1993 (Nicholson, 2001, Hiernaux et al. 2009), since then, rainfall in the region has fluctuated (Frappart et al. 2009). The climate in the region is characterized by a unimodal rainfall regime controlled by the West African Monsoon (Nicholson 1981).Long-term decreases in precipitation, linked to anthropogenic climate change, have caused a die-off of mesic tree species, especially following severe and extreme drought events (Allen $e t$ al. 2010). Acacia savannas represent one of the most extensive vegetation types of dry lands in Africa (Traoré et al. 2012). Acacia senegal (L.) Willd. arewidely distributed in the arid and semi-arid regions of Nigeria, and has an enormous ecological and economic importance value for its gum, fodder and timber. One of the most important environmental factors constraining growth and productivity of plants is drought (Anjum et al. 2011, Lidon and Cebola, 2012).The relative survival of trees on arid and semi- arid land largely depends on the selection of suitable species and populations for drought tolerance. In stress environments, performance in terms of development, growth and yield depends on the plant's ability to withstand, acclimate or recover. Tree species growing in arid conditions have evolved many physiological, morphological and anatomical adaptation mechanisms to cope with water deficit and drought (Arndt et al. 2001, Mundree et al. 2002). The regulation of photosynthetic activity may be a necessary adaptation enabling stress resistant plants to avoid photo damage during exposure to drought (Toivonen and Vidaver 1988). One tool widely used to examine photosynthetic performance in plants is chlorophyll (Chl) fluorescence (Guidi and Degl'Innocenti 2011, Baker 2008, Woo et al. 2008). Chl fluorescence analysis is widely used to estimate photosysthesis II (PSII) activity, which is an important location of abiotic stress (Guidi and Degl'Innocenti 2008, Hogewoning and Harbinson 2007, Lichtenthaler et al. 2007). The aim of the present study is to contribute to a better understanding of the growth variation of $A$. senegal seedlings underwater stress, and how the ability to cope with drought stress may be related to 
the provenances of the trees. The aim of the present study is to contribute to a better understanding of the growth variation of $A$. senegal seedlings underwater stress, and how the ability to cope with drought stress may be related to the provenances of the trees by evaluating the effects of water deficit on growth, biomass allocation and photosynthesis of $A$. senegal seedlings in a greenhouse condition.

\section{MATERIAL AND METHODS}

Plant material: Acacia senegalL.) Willd. (Synonym Senegalia senegal (L.) Britton) germplasm seeds were collected from two provenances in Yobe State, Nigeria incorporating two principal ecological zones of the state; Nguru (arid) of sahelian ecology and Gujba (semi-arid zone) in the sudanian ecological zone. Seeds were obtained from the Rubber Research Institute of Nigeria, Gum Arabic Sub-station Gashua, located at $12^{\circ} 46^{\prime} \mathrm{N}$ and $11^{\circ} 00^{\prime} \mathrm{E} 360 \mathrm{~m}$ altitude. Acacia seeds were treated with concentrated sulphuric acid $\left(\mathrm{H}_{2} \mathrm{SO}_{4}\right) \quad(95 \%)$ for five minutes, then washed thoroughly with distilled water and dried. The seeds were kept for germination in Petri dishes over moist filter paper which were regularly moistened to avoid drying out. All dishes were kept in a hybridiser at an average temperature of $27^{\circ} \mathrm{C}$. The seeds germinated at 5-8 days and were transplanted to $30 \mathrm{~cm} \times 110 \mathrm{~mm}$ PVC stand tubes.

Soil preparation and soil tubes: The soil used for the experiment was Rolawn Blended top loam soil. Ninety $110 \mathrm{~mm}$ diameter PVC stand tubes made of polyvinyl chloride guttering pipes were cut to $30 \mathrm{~cm}$ with holes drilled at $10 \mathrm{~cm}$ and $25 \mathrm{~cm}$ heights from the top on each tube (for insertion of Theta Probe Soil Moisture sensor to measure the volumetric water content) and lined by plastic sleeves. The plastic sleeves could easily be pulled off at harvest to remove the soil body from the tubes without damaging the roots. The bottom of each tube was fitted with $1 \mathrm{~mm}^{2}$ plastic mesh attached by heavy-duty sticking tape. Tubes were then filled with $2000 \mathrm{~g}$ of saturated soil at uniform dry bulk density of $1.1 \mathrm{~g} \mathrm{~cm}^{-3}$. The water content (GWC) was determined by drying the soil to constant weight and measuring the soil sample before filling the tubes. The GWC was determined as in equation 1. In $2000 \mathrm{~g}$ of Rolawn Blended top loam soil, $35.85 \%$ was water, soil was $64.15 \%(=1283 \mathrm{~g}$ of soil). The target weights were $1971.32 \mathrm{~g}$ at $25 \%$ (control), $1952.2 \mathrm{~g}$ at $15 \%$ (mild drought) and 1928.3 $\mathrm{g}$ at $10 \%$ (severe drought) GWC. During the experiment, any change in the volumetric water content for all the tubes was monitored by weighting at a weekly interval. The same electronic balance with an accuracy of $\pm 0.01 \mathrm{~g}$ was used throughout the experiment.

After 6 weeks at $25 \%$ GWC, watering was withheld in the drought tubes to allow them to reach the target GWC for each treatment, $15 \% \mathrm{GWC}$ for mild drought and $10 \%$ for severe drought. When these had reached their target weight at 10 days of drought, they were rewatered to maintain the desired targets of GWC after water loss by evapo-transpiration according to amount of water loss by weight.

Soil volumetric water content was measured at $10 \mathrm{~cm}$ and $25 \mathrm{~cm}$ depth using a calibrated theta probe DeltaT Devices (ML2x) (Delta-T devices, Cambridge, UK.) with four rods of $60 \mathrm{~mm}$ length and was recorded weekly.

$$
G W C=\frac{(\text { weight of wet soil })-(\text { weight of dried soil })}{(\text { turgid weight of dried soil })-(\text { weight of dried soil })} \quad X 100
$$

Soil Analysis: Soil moisture content at depths of $10 \mathrm{~cm}$ and $25 \mathrm{~cm}$ (Figure 1) revealed a significant difference $(\mathrm{P} \leq 0.001)$ in $\mathrm{GWC}$. The three treatments appeared to be correctly applying different drought effects as expected throughout the depth of the pots.

Experimental design: There were three treatments (watering regimes); fully watered (control), mild drought and severe drought with two factors (provenances and watering regime). Replication was $\mathrm{n}=15$ for all treatments. Altogether there were 90 tubes, which were divided in three blocks, one block per treatment. The replicates were assigned to a block and arranged completely randomly within a block. All tubes were weighed and labelled. One pre-germinated seed of each provenance (Nguru and Gujba) was sown in each tube. Position of pots was changed randomly within the block on alternate days to maintain uniformity in light conditions and blocks were reassigned to new positions bi-weekly. Water use was monitored every alternate day by weighing the tubes and the amount of water added every week was the average amount used by plant tubes. To avoid leaching from bottom of tubes, leached water was replaced carefully by sprinkling gently not to damage soil surface profile using a $50 \mathrm{ml}$ water dispenser connected to 11 glass bottle. The experiment was conducted in a greenhouse for seventeen weeks in March and July, 2013 at the School of Biological Sciences, University of Aberdeen, Scotland, UK. During the experiment, the average day/night temperature was $27 / 24^{\circ} \mathrm{C}$; relative humidity ranged 
from 50 to $70 \%$ and the photoperiod was 8 hours of $300 \mu \mathrm{mol} \mathrm{m} \mathrm{m}^{-2} \mathrm{PAR}$ (photosynthetic active radiation) at plant foliage height.

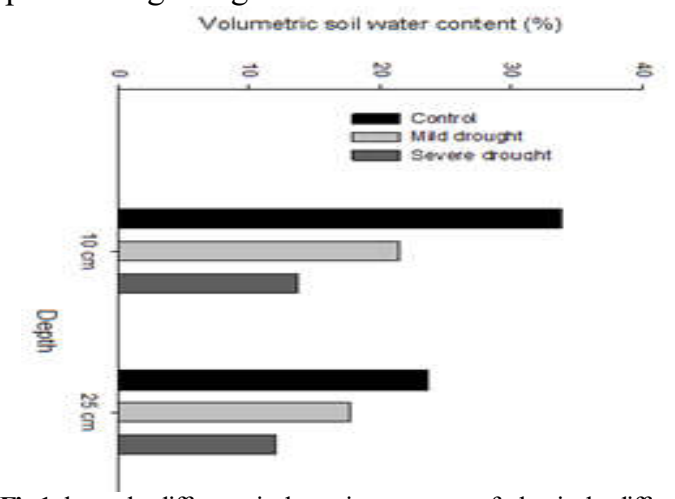

Fig 1 shows the difference in the moisture content of tubes in the different treatments of control, mild and severe drought at $10 \mathrm{~cm}$ and $25 \mathrm{~cm}$ depth, respectively, indicated consistent difference between treatments

Plant growth and physiology: At Week 10 of plant growth (4 weeks into the drought treatment) and two weeks to the end of drought application (at Week 15) stomata conductance $\left(\mathrm{mmol} \mathrm{m} \mathrm{m}^{-2} \mathrm{~s}^{-1}\right)$ in the youngest fully expanded leaf (lower surface) of all plants in the control and drought treatments was measured at midday (10:00-14:00 when gs was expected to be at peak values (Ullmann, 1989)), using an AP4 porometer (Delta-T Devices, Cambridge, UK).The pinnate leaves of $A$. Senegal were carefully arranged in parallel to fill the leaf chamber (Figure 2).

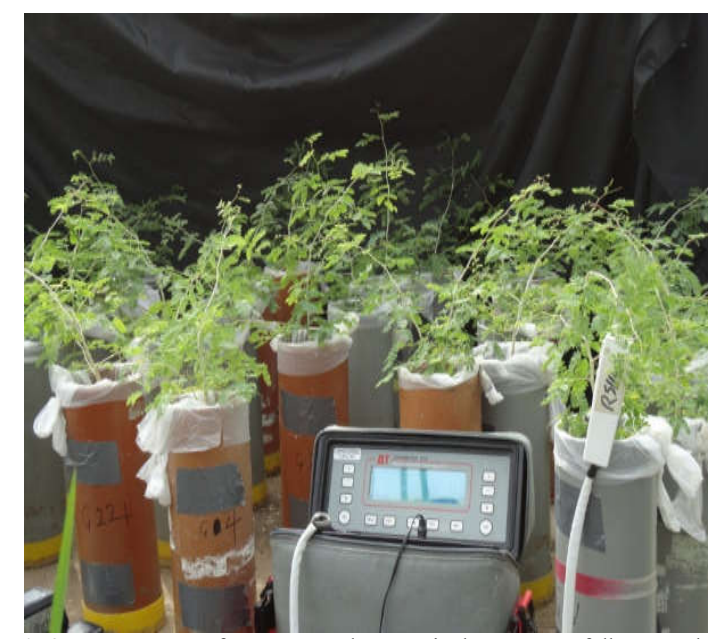

Fig 2 Measurement of stomata conductance in the youngest fully expanded leaflet

To evaluate plant water status during the stress period, relative water content (RWC) was used, determined according to Barrs and Weatherly (1962). Cut leaves were weighed (fresh weight, FW), then kept moistened in drops of distilled water at room temperature for 24 hours to saturate and their turgid weights (TW) were calculated. The samples were then dried in an oven at $80{ }^{\circ} \mathrm{C}$ for 24 hours and weighed (DW). The RWC was determined as follows:

$$
R W C=\frac{(F W-D W)}{(T W-D W)} X 100
$$

Where: $\mathrm{RWC}=$ relative water content, $\mathrm{FW}=$ fresh leaf weight, $\mathrm{DW}=$ dry leaf weight and $\mathrm{TW}=$ turgid weights.

At 17 weeks after sowing, plants were harvested. A day before harvest chlorophyll fluorescence and quantum yield (a measure of the maximum photochemical efficiency of Photosystem (II)) were measured. To measure chlorophyll fluorescence and quantum yield whole plantswere moved to the laboratory and kept in a dark room for 10 minutes at room temperature to provide a dark period and then fluorescence was measured with a fluorescence meter (Fluorpen, Qubit system Inc. Kingston, Ontario Canada) on the second youngest fully expanded leaf (lower surface) of all plants in the control and drought treatments. At the end of the experiment, shoots were removed at the base and roots were thoroughly washed of soil particles. Total root length was determined by laying out the washed roots on a flat surface and measurement was taken with a metre rule before drying in $80^{\circ} \mathrm{C}$ oven to obtain dry weight. Shoot dry mass and root dry mass were determined. Root/shoot mass ratio and total plant biomass were calculated.

Data analysis: Two-way analysis of variance (ANOVA) was carried out to test any differences among treatments. Significance levels were taken at $5 \%$ level. Correlations were conducted between stomatal conductance and root length to identify any significant relationships between the two variables. All analyses were performed using the statistical software MINITAB ${ }^{\circledR}$ Release 16.12.0.\& SigmaPlot $^{\circledR}$ Release 12.0). A normality test was performed on all the data, which were log-transformed in cases where residuals were not normally distributed.

\section{RESULTS AND DISCUSSION}

Stomata Conductance: There was a highly significant difference in stomata conductance among the treatments $\left(\mathrm{F}_{2,84}=11.38, \mathrm{P}<0.001\right)$ in relation to water deficit. The control in each provenance was higher than the drought treatments (Figure 3) 10 weeks after the application of drought treatment. There was also a significant difference between the two provenances the Gujba provenance was higher in conductance than the Nguru provenance $\left(\mathrm{F}_{2,84}=14.86, \mathrm{P}<0.001\right)$. There was no interaction between treatment and provenance $\left(\mathrm{F}_{2,84}=0.28, \mathrm{P}=0.754\right)$. 


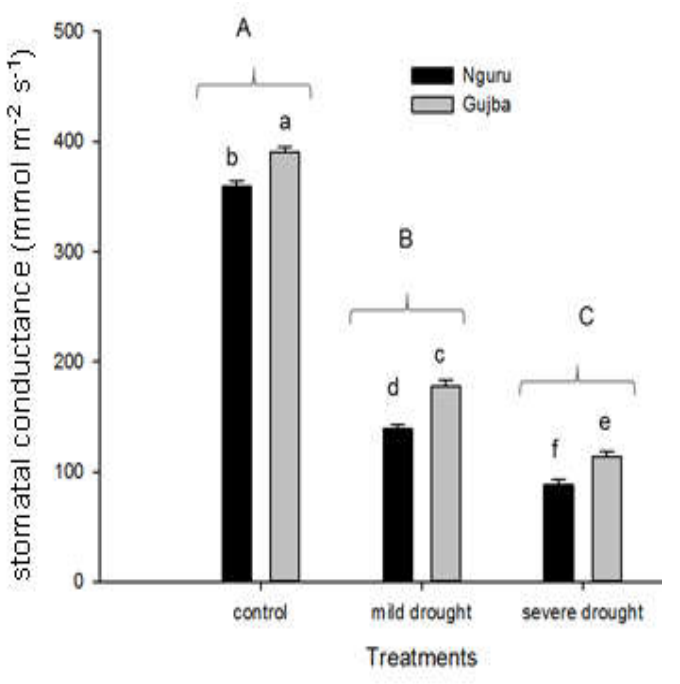

Fig 3 Mean ( \pm SE) stomatal conductance of $A$. senegal provenances at Week 15 (10 weeks drought application) $n=15$.Means with different letter are significantly different among treatments (uppercase) and within treatments between the provenances (lowercase) after a Tukey test $(\mathrm{P}<0.05)$.

Correlation: Correlation between stomatal conductance and root length (Figure 4) for the various treatments (control, mild drought and severe drought) show significant positive correlation $(\mathrm{r}=0.71, \mathrm{P}<$ $0.001)$. The correlation analysis further showed that $49.51 \%$ of variation in stomatal conductance can be accounted for by the regression model.

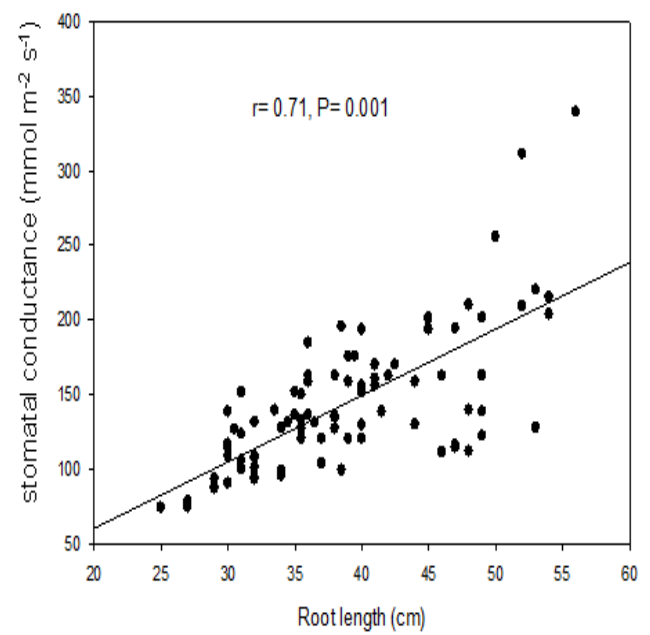

Fig 4. Correlation between stomatal conductance and total root length among the treatments (control, mild drought and severe drought).

Quantum yield: Quantum yield among treatments was negatively affected by water deficit $\left(\mathrm{F}_{2,84}=31.18, \mathrm{P}<\right.$ 0.001 ), at week 17 (Figure 4.). There was no statistical difference in quantum yield between the two provenances $\left(\mathrm{F}_{1,84}=0.15, \mathrm{P}=0.695\right)$ and interaction between treatment and provenances was also not significant $\left(\mathrm{F}_{2,84}=2.14, \mathrm{P}=0.124\right)$. Comparison of stomatal conductance and quantum yield (Figure 5) for the various treatments (control, mild drought and severe drought) show significant positive correlation $(\mathrm{r}=0.27, \mathrm{P}<0.010)$. Correlation explains $49.51 \%$ of variation in the stomatal conductance can be accounted for by the regression model $\mathrm{r}^{2}=(6.21)$.

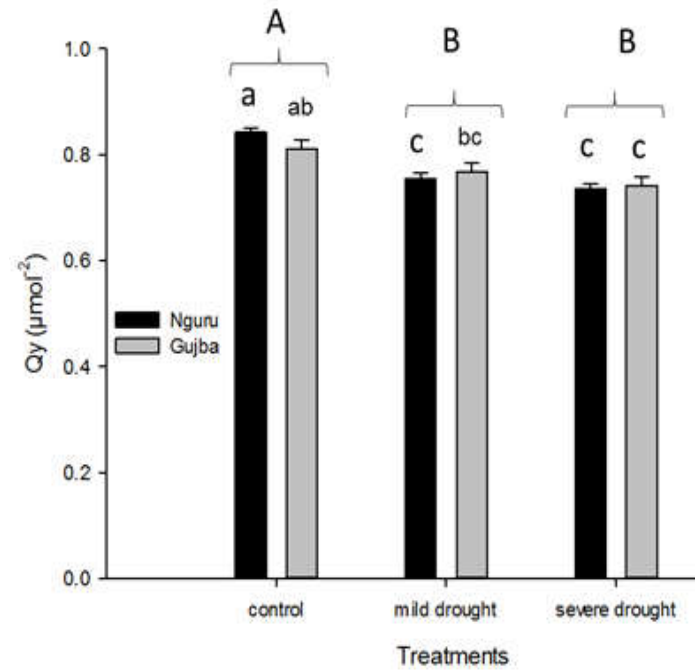

Fig 5. Mean ( \pm SE) quantum yield of PSII photochemistry in two provenances of $A$. senegal at 17 weeks, $\mathrm{n}=15$. Means with different letter are significantly different among treatments (uppercase) but not within treatment the provenances (lowercase) after a Tukey test $(\mathrm{P}<0.05)$.

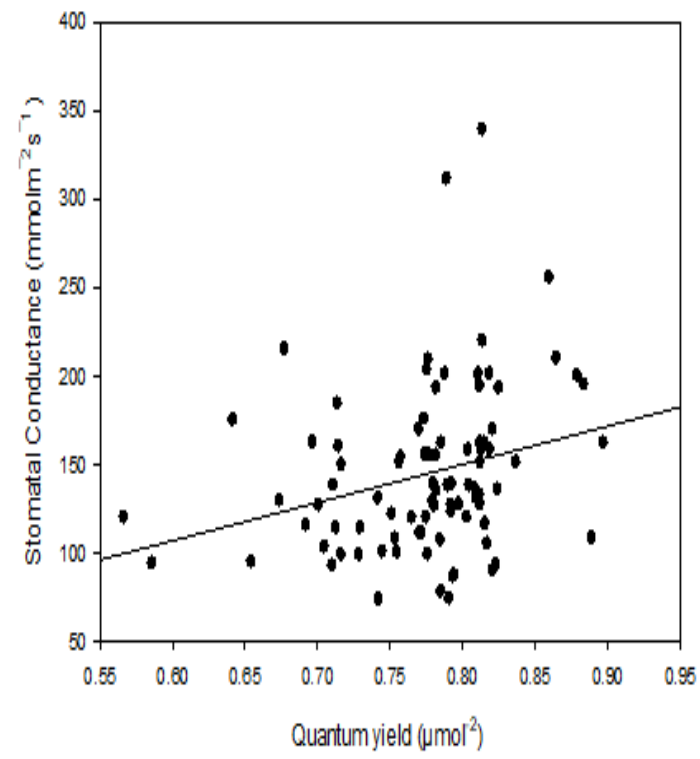

Fig 6. Correlation between stomatal conductance and quantum yield

Chlorophyll Fluorescence: There was a significant effect of water deficit between treatment $\left(\mathrm{F}_{2,84}=54.34\right.$, $\mathrm{P}<0.001$ ) on chlorophyll fluorescence (Figure 7) There were no statistical differences $\left(F_{2,84}=1.97, \mathrm{P}=0.147\right)$ in chlorophyll fluorescence between the two provenances or in interaction between treatments and provenances. 


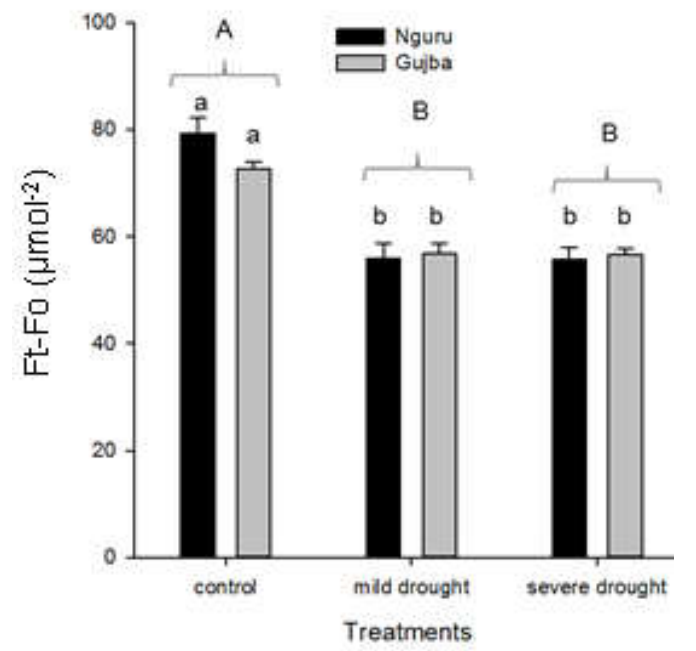

Fig 7 Mean $( \pm$ SE) chlorophyll fluorescence in two provenances of $A$. senegal at 17 weeks, $n=15$. Means with different letter are significantly different among treatment (uppercase) but not within treatment the provenances (lowercase) after a Tukey test $(\mathrm{P}<0.05)$

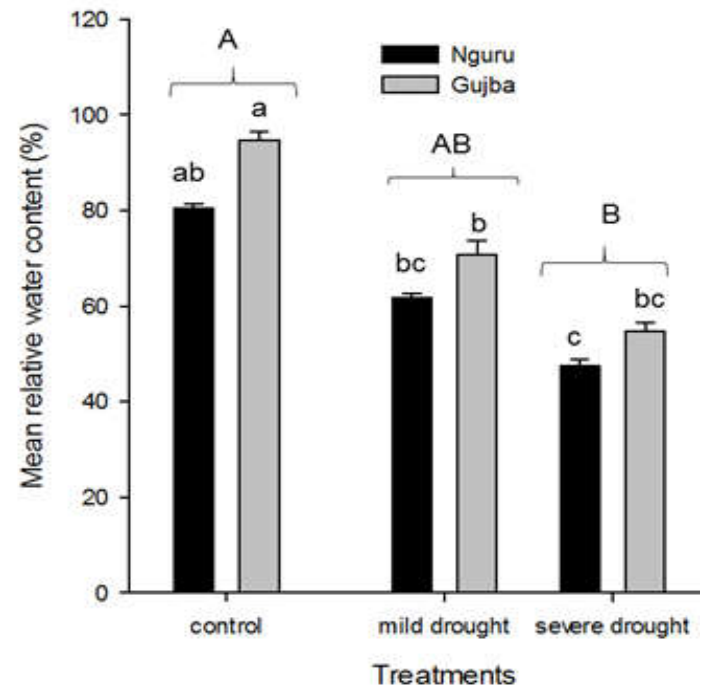

Fig 8 Mean $( \pm \mathrm{SE})$ relative water content between two provenances of $A$. senegal, $\mathrm{n}=5$, Means with different letter are significantly different among treatments (uppercase) but not betweenprovenances within treatments(lowercase) after a Tukey test $(\mathrm{P}<0.05)$.

Relative water content (RWC): There was a significant difference between the treatments and the provenances, $(\mathrm{P}<0.001) \mathrm{RWC}$ in responseto water deficit. The control was higher than the drought treatments (Figures 8).There were no statistical differences $(\mathrm{P}>0.005)$ in interaction between treatment and provenances. But not between provenances within treatments.

Root Length: At the end of the experiment mean root length between the provenances were significantly different $\left(\mathrm{F}_{2,84}=0.60, \mathrm{P}<0.001\right)$, (Figure 9) and the interaction between treatment and provenance was statistically significant $\left(\mathrm{F}_{1,84}=25.31, \mathrm{P}=0.001\right)$. Root lengthwas not statistically significantbetweentreatments $\left(\mathrm{F}_{2,84}=0.60, \mathrm{P}=0.550\right)$.

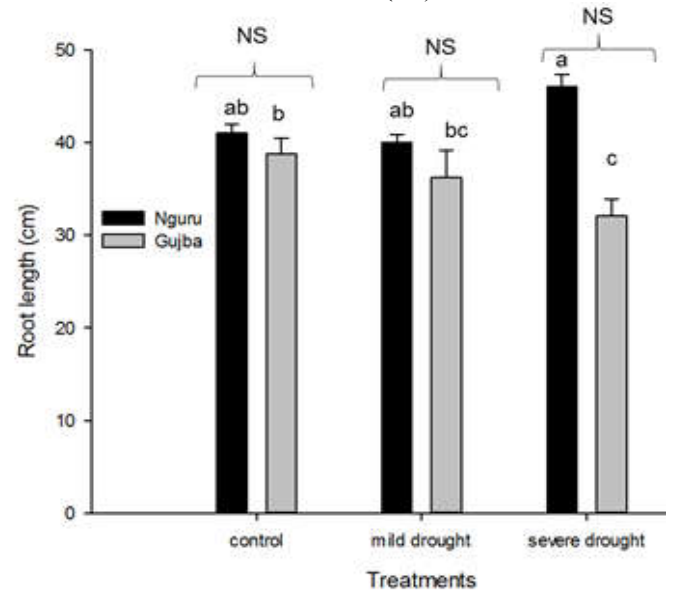

Fig 9 Mean $( \pm \mathrm{SE})$ root lengthof $A$. senegal in two provenances n=15.Means with different letters are significantly different betweenprovenance within treatments (lowercase) after a Tukey test $(\mathrm{P}<0.05)$

Shoot dry weight: Mean shoot dry weightwithin treatments was significantlydifferent $\left(\mathrm{F}_{2,84}=38.30, \mathrm{P}<\right.$ 0.001), (Figure 10). The interaction between treatment and provenance was also significantly different $\left(\mathrm{F}_{2,84}=92.73, \mathrm{P}<0.001\right)$. Water deficit was not significantly different between provenances $\left(\mathrm{F}_{1,84}=\right.$ $6.58, \mathrm{P}=0.012$ ).

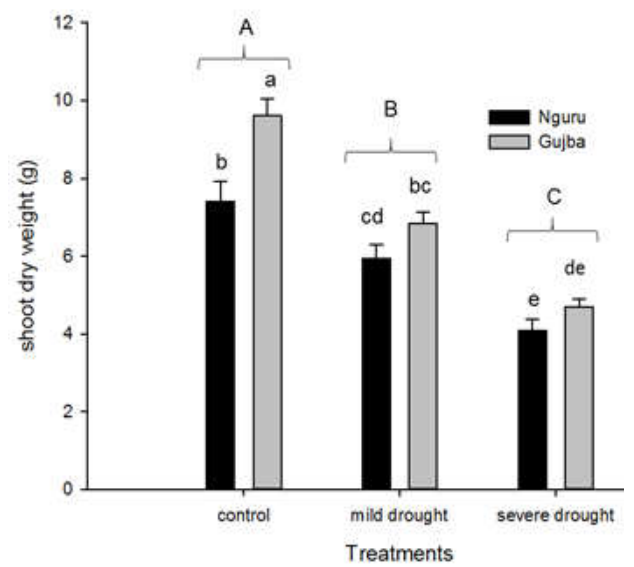

Fig 10 Mean ( \pm SE) Shoot dry weight between two provenances of $A$. senegal, $\mathrm{n}=15$. Means with different letter are significantly different among treatments (uppercase) and between provenances within treatment (lowercase) after a Tukey test $(\mathrm{P}<0.05)$

Root dry weight: Water deficit was significantly different on root dry weight within treatments $\left(\mathrm{F}_{2}, 84=\right.$ $14.15, \mathrm{P}<0.001)$ and between the provenances $\left(\mathrm{F}_{2,84}\right.$ $=18.65, \mathrm{P}<0.001$ ), (Figure 4.12). There were no statistical differences $\left(\mathrm{F}_{2}, 84=0.27, \mathrm{P}>0.765\right)$ in interaction between treatment and provenances. 


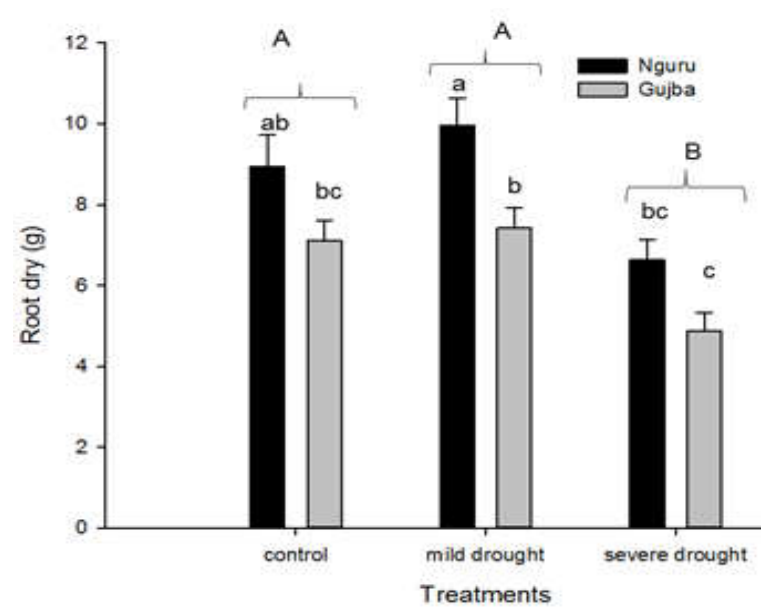

Fig 11. Mean ( \pm SE) root dry weight two provenances of $A$. senegal, $\mathrm{n}=15$. Means with different letter are significantly different among treatments (uppercase) and between provenances within treatments (lowercase) after ANOVA and Tukey test $(\mathrm{P}<0.05)$

Root:Shoot Ratio: Root: shoot ratios between treatments werestatistically significant $\left(\mathrm{F}_{2,84}=26.25\right.$, $\mathrm{P}<0.001$ ) at the end of the experiment (Figure 12). There was also a statistical significant difference between the two provenences $\left(\mathrm{F}_{1,84}=54.53, \mathrm{P}<0.001\right)$. The interaction between treatment and provenance was not statistically significant $\mathrm{F}_{2,84}=2.54, \mathrm{P}=0.085$.

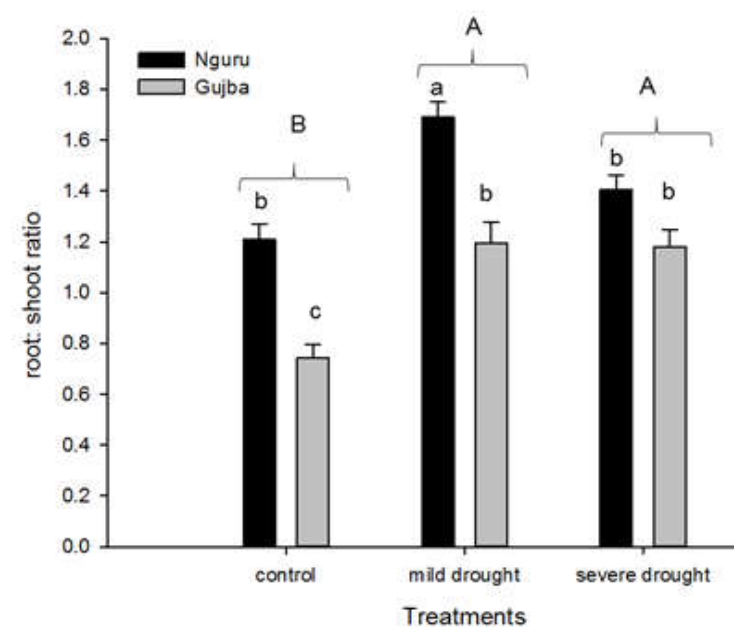

Fig 12 .Mean ( \pm SE) root: shoot ratio between two provenances of $A$. senegaln=15.Means with different letter are significantly different among treatments (uppercase) and between provenances within treatment (lowercase) after a Tukey test $(\mathrm{P}<0.05)$.

The importance of water deficit on the growth of Acacia seedlings was observed using a range of variables. There were differences in the pattern of growth between the provenances (arid and semiarid).Results supported those of Elfeel and Al-Namo (2011), who reported that drought significantly reduced growth traits in Acacia tortilis, Salvador persica and Leptadenia pyrotechnicain a nursery.
Similarly, reduced growth of Acacia seedlings in response to water stress have been observed in other studies (Aref and El-Juhany, 2005 \& 1999; El Atta et al.,2012).Similar results have been reported in a similar greenhouse experiment using potted seedlings of Acacia albida (Del) and Acacia seyal (Del) subjected to three soil moisture regimes (Awodola 1991). Water deficit has been showed to decrease with relative water content (Liu et al., 2004; Merchant et $a l ., 2007)$. The relative water content decreased when the water was deficient in this study. The RWC values of $A$. Senegal from two provenances were reduced under drought stress, the highest reduction in RWC was obtained from the severe drought. Results of this study showed a pattern similar to those of others involving Acacia spp. (Liu et al. 2004, Merchant et al. 2007; Abdelbasit et al. 2012). There is a relationship between relative water content and drought resistance (Abdelbasit et al. 2012) and decrease in relative water content is assumed to result in stomatal closure (Cornic 2000). Acacia species from two provenances in this study showed that stomatal conductance decreased under water deficit condition compared with the well-watered condition. Results of this study showed a pattern similar to those of other studies involving Acacia spp. (Otieno et al. 2005, Davies et al. 1992, Arndt et al. 2001, Liang and Zhang 1999, Liu et al.2004). The results of this study and several others (Chaves et al. 2002; Aasamaa and Sober 2011, Tsegay et al. 2014) indicate that responsive stomata and a deep root system in $A$. senegal both seem to increase the ability of the tree to endure drought for a considerable period without becoming severely dehydrated (Kramer 1980). The results of this study also showed that there is a positive correlation between stomatal conductance and root length. This indicates that an increases in root length can be associated with increased stomatal conductance. This effect would be an example of plasticity in root length in response to drought in this species. A decline in stomatal conductance, for example in response to water deficit, is associated with decrease in the quantum yield of PSII photochemistry (Fv/Fm ratio) (Hussain et al. 2011;Guidi and Degl'innocenti 2011). In this study Fv/Fm values decreased in water deficit conditions compared to those in well-watered conditions. A similarpattern of $\mathrm{Fv} / \mathrm{Fmhas}$ been observed in ofseedlings of Allocasuarina luehmannii which significantly decreased due to drought stress (Guidi and Degl'innocenti 2011). Results of this study showed that there is a correlation between quantum yield and stomatal conductance which indicates that when quantum yield increases stomatal conductance also tends to increase in the tested treatments. Water stress in this study was associated with an increased allocation of dry matter to the roots, Shoot dry mass 
and root/shoot ratios revealed apparent differences in growth response between provenances. Nguru (arid) provenances had longer roots than the Gujba (semiarid) provenances. Water stress also affects total biomass allocation between the two provenances. This finding corresponds with the results on the effect of watering regime on early growth of four different provenances of $A$. senegal. The arid provenance performed better when watered once in three days, then the semi-arid provenance when watered once in two days. (Isah et al. 2013). Large differences in biomass allocation as a result of water stress have also been observed in seedlings of $A$. tortilis from different habitats in Kenya (Otieno et al. 2001). Similarly, biomass allocation in A. tortolis from different provenances in Sudan were affected by water stress (Abdelbasit et al. 2012). In water limiting conditions the allocation of biomass tends to be modified in favour of root growth, leading to an increase in root dry weight and consequently the root to shoot ratios (Madhu and Hatfield 2013; Aref and El-Juhany 1999). Droughted $A$. senegalof the Nguru provenances had a significantly lower shoot dry weight but higher root dry weight than the Gujba provenances. This finding corresponds with the results of $A$. senegal seedlingson sandy soil in western Sudan (Mohamed 2005).Several studies have indicated increase inroot dry weight as a result of water stress in other Acacia species (Elfeel and Al-Namo 2011,Aref and El-Juhany, 2005, 1999; El Atta et al. 2012, Awodola 1991)

Conclusions: The mechanisms by which Acacia species responded to significant soil drying seem to involve conservation of water by investment of more biomass to roots, less biomass to shoots presumably resulting in a reduction of transpiring surface and a reduction in midday stomata conductance. The survival of $A$. senegal seedlings in realistic soil drying conditions during a 120 days experimental period indicates a degree of drought tolerance and the ability of the species to acclimate to a ranges of water level by morphological and plastics response.

\section{REFERENCES}

Aasamaa, K; Sober, A (2011) Responses of stomatal conductance to simultaneous changes in two environmental factors, Tree Physiology, (31) 8. 855-864

Abdelbasit, HE; Sadya, M; Ahamed, E. (2012). Variation in Drought Tolerance and Survival among Three Provenances of Acacia tortilis Subspecies Raddiana and Subspecies Spirocarpa Seedlings. Asian Journal of Agricultural Sciences 4(2): 134-139
Allen, CD; Macalady, AK; Chenchouni, H; Bachelet, D; McDowell, N; Vennetier, M; Cobb, N (2010). A global overview of drought and heat-induced tree mortality reveals emerging climate change risks for forests. Forest Ecology and Management, 259(4), 660-684.

Anjum, SA; Xie, X; Wang, L; Saleem, MF; Man, C; Lei, W (2011) Morphological, physiological and biochemical responses of plants to drought stress, Afri. J Agric. Res.. 6. 9. 2026-2032.

Aref, IM, El-Juhany, LI (1999). Effects of water deficit on the growth of Acacia asak, A. tortilis and A. gerrardi. Mansoura Univ. J. Agric. Sci. 24 (10): 5627-5636.

Aref, IM; El-Juhany,LI (2005). Growth response of Acacia seyal, Acacia negrii and Acacia asak seedling to water stress under field conditions. Journal of King Saud University, Agriculture Sciences. 17(2): 75-83.

Arndt, S; Clifford, S; Wanek, W; Jones, H; Popp, M (2001). Physiological and morphological adaptations of the fruit tree Ziziphus rotundifolia in response to progressive drought stress. Tree physiology, 21(11).705-715.

Awodola, AM; (1991) The effect of soil moisture regime on growth of Acaciaalbida and Acacia seyal seedlings. Nig. J. Forest.21 (1\&2) 35-37.pp

Baker, NR (2008) Chlorophyll fluorescence: a probe of photosynthesis in vivo. Annual Review of Plant Biology. 59, pp. 89-113.

Barrs, HD; Weatherley, PE (1962) A re-examination of the relative fargidity technique for estimating water deficits in leaves. Aust. J. Biol. Sci. 15, 413-428.

Chaves, MM; Maroco, JP; Pereira, JS (2003) Understanding plant responses to drought - from genes to the whole plant. Functional plant Biol. 30. (3). 239-264

Chaves, MM; Pereira, JS; Maroco, J; Rodrigues, M; Osorio, M; Carvalho, I; Faria, T; Pinheiro, C (2002) How plants cope with water stress in the field? Photosynthesis and growth. Annals of Botany, 89(7). 907-916.

Cornic, G (2000) Drought stress inhibits Photosynthesis By decreasing stomatal aperture- 
Not by affecting ATP synthesis. Trends plant science. 5: 187-198.

Craven, D; Gulamhussein, S; Berlyn, GP (2010) Physiological and anatomical responses of Acacia koa (Gray) seedlings to varying light and drought conditions. Environmental and Experimental Botany, 69 (2). 205-213.

Davies, FT; Potter, JR; Linderman, PG (1992) Mycorrhiza and repeated drought exposure affect drought resistance and extraradical hyphae development of pepper plants independent of plant size and nutrient content. Journal of Plant Physiology 139: 289-294.

El Atta, HA; Aref, IM; Ahmed, AI; Khan, PR (2012) Morphological and anatomical response of Acacia ehrenbergiana Hayne and Acacia tortilis (Forssk) Haynes subspp. raddiana seedlings to induced water stress. Afri. J. Biotechnol. 11(44). 10188-10199, 31

El feel, A; Al-Namo, ML (2011) Effect of imposed drought on seedlings growth, water use efficiency and survival of three arid zone species (Acacia tortilissubsp raddiana, Salvadora persica and Leptadenia pyrotechnica). Agriculture \& Biology Journal of North America. 2. 3.

Frappart, F; Hiernaux, P; Guichard, F; Mougin, E; Kergoat, L; Arjounin, M; Lavenu, F; Koité, M; Paturel, J; Lebel, T (2009) Rainfall regime across the Sahel band in the Gourma region, Mali, Journal of Hydrology. 375. 1. 128-142.

Guidi, L; Degl'Innocenti, E (2008) Ozone effects on high light-induced photo inhibition in Phaseolus vulgaris, Plant Science. 174. 6. 590-596.

Guidi, L; Degl'innocenti, E (2011) Imaging of Chlorophyll a Fluorescence: A Tool to Study Abiotic Stress in Plants.

Hiernaux, P; Diarra, L; Trichon, V; Mougin, E; Soumaguel, N; Baup, F (2009) Woody plant population dynamics in response to climate changes from 1984 to 2006 in Sahel (Gourma, Mali) J. Hydro. 375 (1) 103-113.

Hogewoning, SW; Harbinson, J; (2007) Insights on the development, kinetics, and variation of photoinhibition using chlorophyll fluorescence imaging of a chilled, variegated leaf, J. Expt. Bot. 58. 3. $453-463$
Hussain, MI; González, L; Souto, C; Reigosa, M (2011) Ecophysiological responses of three native herbs to phytotoxic potential of invasive Acacia melanoxylon R. Br., Agroforestry Systems. 83. 2. $149-166$

IPCC, 2007: Climate Change (2007) The Physical Science Basis. Contribution of Working Group I to the Fourth Assessment Report of the Intergovernmental Panel on Climate Change [Solomon, S; Qin, D; Manning, M; Chen, Z; Marquis, M; Averyt, KB; Tignor, M; Miller, HL (Eds.)]. Cambridge University Press, Cambridge, United Kingdom and New York, NY, USA

Isah, A; Bello, A; Maishanu, H; Abdullahi, S (2013) Effect of watering regime on the early growth of Acacia senegal (linn) willd. Provenances. International Journal of Plant, Animal and Environmental Sciences. 3 (2). 52-56

Kramer, PJ (1980) Drought, stress and the origin of adaptation. In Adaptation of Plants to Water and High Temperature Stress (ed. Turner, N.C.). John Wiley \& Sons. pp. 7-20.

Landsberg, J (1999). Relationships between water use efficiency and tree production. The ways tree use water. Water and salinity issues in agroforestry. 5 . 45-54.

Liang, J; Zhang, J (1999) The relations of stomatal closure and reopening to xylem ABA concentration and leaf water potential during soil drying and rewatering, Plant growth regulation, vol. 29. 1-2. 77-86.

Lichtenthaler, HKA; Marek, MV; Kalina, J; Urban, O (2007) Differences in pigment composition, photosynthetic rates and chlorophyll fluorescence images of sun and shade leaves of four tree species, Plant Physiology and Biochemistry. 45. 8. 577-588.

Lidon, ZZ, Cebola, F (2012). An overview on drought induced changes in plant growth, water relations and photosynthesis. Emirates Journal of Food and Agriculture, 24(1). 57-72.

Liu, Li-Xia; Xu, Shou-Min; Woo, KC (2004) Watering regime effects on photosynthsis and the xanthophyll cycle in the tropical tree species Acacia auriculiformis in North Australi, N. Zealand J. Bot. 42: 949-957. 
Madhu, M; Hatfield, J (2013) Dynamics of Plant Root Growth under Increased Atmospheric Carbon Dioxide. Agronomy Journal, 105(3). 657-669.

Merchant, A; Callister, A; Arndt, S; Tausz, M; Adams, M (2007) Contrasting physiological responses of six Eucalyptus species to water deficit. Ann. Bot. 100: $1-9$.

Mohamed, AG (2005) Improvement of traditional Acacia senegal agroforestry: Ecophysiological characteristics as indicators for tree-crop interaction on sandy soil in western Sudan. University of Helsinki.

Mundree, SG; Baker, B; Mowla, Peters, S; Marais, S; Willigen, CV; Govender, K; Maredza, A; Muyanga, $\mathrm{S}$;

Farrant, JM (2002) Physiological and molecular insights into drought tolerance, Afr. $J$. Biotechnol.. 1. 2, pp. 28-38.

Nicholson, SE (1981). The historical climatology of Africa. Wigley, TML; Ingram, MJ; Farmer G. (Eds.), Climate and History, Cambridge Press pp. 249-270

Nicholson, SE (2001). Climate and environmental change in Africa during the last two centuries. Climate Research 14:123-144.

Otieno, DO; Schmidt ,MW; Adiku, S; Tenhunen, J (2005) Physiological and morphological responses to water stress in two Acacia species from contrasting habitats, Tree Physiology, 25, (3). 361-371.

Otieno, DO; Kinyamario, JI; Omenda, TO (2001) Growth features of Acacia tortilis and Acacia xanthophoea seedling and their response to cyclic soil drought stress. African Journal of Ecology. 39(21): 126-132.
Socias, X; Correia, M; Chaves, M; Medrano, H (1997). The role of abscisic acid and water relations in drought responses of subterranean clover, Journal of experimental botany. 48. 6 . 1281-1288.

Stave, J; Oba, G; Eriksen, AB; Nordal, I; Stenseth, NC (2005) Seedling growth of Acacia tortilis and Faidherbia albida in response to simulated groundwater tables. Forest Ecology and Management, 212(1). 367-375.

Toivonen, P; Vidaver, W (1988) Variable Chlorophyll a Fluorescence and $\mathrm{CO}(2)$ Uptake in WaterStressed White Spruce Seedlings, Plant Physiology. 869(3). 744-748.

Traoré, S; Zerbo, L; Schmidt, M; Thiombiano, L (2012) Acacia communities and species responses to soil and climate gradients in the SudanoSahelian zone of West Africa. Journal of Arid Environments, 87, 144-152.

Tsegay, D; Amsalem, D; Almeida, M; Crandles, M (2014) Responses of grapevine rootstocks to drought stress, International Journal of Plant Physiology and Biochemistry. 6. 1, pp. 1-6.

Ullmann, I (1989). Stomatal conductance and transpiration of Acacia under field conditions: similarities and differences between leaves and phyllodes. Trees, 3(1). 45-56.

Woo, NS; Badger, MR; Pogson, BJ (2008) A rapid, non-invasive procedure for quantitative assessment of drought survival using chlorophyll fluorescence. Plant Methods, 4(1). 27. 